\title{
Engaging fathers in child welfare services: a narrative review of recent research evidence
}

\author{
Nina Maxwell*, Jonathan Scourfield*, Brid Featherstone $\uparrow$, Sally Holland* and Richard Tolman \\ *School of Social Sciences, Cardiff University, Cardiff, †Health and Social Care, Open University, Milton Keynes, UK, \\ and $¥$ School of Social Work, University of Michigan, Ann Arbor, MI, USA
}

Correspondence:

Jonathan Scourfield,

School of Social Sciences,

Cardiff University,

Cardiff CF10 3WT,

UK

E-mail: scourfield@cardiff.ac.uk

Keywords: child protection, child welfare, fathers/fatherhood, gender

Accepted for publication: January 2012

\begin{abstract}
It is widely recognized as problematic that there are generally low levels of engagement with child welfare services from biological and social fathers. The result can be limited resources for children's care and potentially poor risk assessment and management. This paper reviews the published research from 2000 to 2010 about the barriers to and facilitators of better father engagement, as well as the very limited evidence on the effectiveness of work with maltreating fathers. There is relatively little known about what works in engaging men, but there are some promising indicators from family support and child protection practice contexts. These include early identification and early involvement of fathers; a proactive approach, including an insistence on men's involvement with services; and the use of practical activities. In the light of what is known about the characteristics of maltreating fathers, there is a logical fit with cognitivebehavioural approaches. Although there is no direct evidence of the effectiveness of motivational interviewing in this context, its effectiveness in allied fields of practice would suggest that it may hold some promise for the initial engagement of fathers who pose a risk to children.
\end{abstract}

\section{INTRODUCTION}

Interest in fathers' involvement in child welfare services has increased in recent years. There seems to have been a certain modest flourishing of practice initiatives and research in several different countries. This paper aims to synthesize the recent international research evidence on father engagement, presenting the findings of a narrative research review. This is not the first research review of the field; there are others (see Ryan 2000, 2006; Sonenstein et al. 2002), as well as books which have given a scholarly overview of research, theory and practice (Daniel \& Taylor 2001; Featherstone 2009). However, the current review is a useful contribution, as in comparison with previous research reviews, it provides a more up-to-date summary of an expanding field and is more comprehensive in its search strategy than some previous reviews. It is also focused on an important aspect of the theme of this special issue.

The review focused on evidence from 2000 to 2010 about the barriers and facilitators of father engagement in services as well as which approaches have been found to be most effective in interventions for maltreating fathers. The term 'fathers' being used here includes any male with a child caretaking role, whether a biological father or a 'social father' such as a stepfather or mother's partner. The review's scope goes beyond the context of child protection, as insights relevant to engaging fathers can also be found in research on parenting support. For this reason, the broader term 'child welfare' is used in the paper. There is, however, a particular focus on risk, this being the theme of the special issue. The review primarily aims to describe the substantive themes emerging from recent research, rather than present methodological 
critique, but there are some concluding comments about what kinds of additional evidence might be needed.

It is widely recognized that there tends to be relatively poor engagement of fathers in child welfare services and this is thought to be detrimental, either because a man's potential (and that of his wider family) to be a resource for the care of children is not used and/or because the risk posed by a man to children is not properly assessed and managed. In the course of child protection work, social workers can feel as though they are bombarded with men who are posing a risk to children, through physical abuse, sexual abuse and emotional maltreatment (Scott \& Crooks 2004). Fathers may be intimidating or intoxicated and abusive to workers, leading workers to be reluctant to confront or engage with them or to purposefully avoid them for fear of their violent reactions (O'Donnell et al. 2005). In this context, it is perhaps not surprising that men can be perceived as being dangerous non-nurturers (Ferguson \& Hogan 2004). If, however, men are labelled as violent without recognition of their role as fathers, this not only negates any chance of changing the negative aspects of these fathers' behaviours to children but also may do little to stop them from leaving the home and moving on to new relationships with new children, both their own and their stepchildren. This paper adopts the position that, '. . . [t] o move toward true inclusiveness in both protecting and supporting children, practitioners need to proactively assess and engage with all significant men in a child's life, understanding that some may pose risks, some may be assets and some may incorporate aspects of both' (Strega et al. 2008, p. 713; see also Daniel \& Taylor 2001).

\section{METHOD}

There are a number of methods for reviewing evidence in a specific field. Commonly, distinctions are made between a systematic review, in which all primary evidence that meets clear inclusion criteria is retrieved and its quality appraised using explicit and reproducible methodology, and narrative reviews which do not always make clear the inclusion criteria or methods for appraisal (MacDonald 2003). However, in defence of narrative reviews, Collins \& Fauser (2004) note they can have the advantage over systematic reviews of tackling more comprehensive topics. These authors call for narrative reviews to be strengthened by adopting some of the techniques of systematic reviews such as transparency in reporting methods. We have chosen to describe this review as a narrative review to signal that it does not follow the full protocol of a systematic review. Nonetheless, we have aimed to follow Collins and Fauser's advice in laying out clearly our search strategy and methods of analysis.

The literature review has clear aims and is based on a defined search strategy. The research questions were as follows:

- What are the barriers to and facilitators of better father engagement in child welfare services?

- What is the evidence on the effectiveness of work with maltreating fathers?

The search was conducted from July to September 2010 and included a range of national and international databases: The International Bibliography of the Social Sciences, Social Science Citation Index, CINAHL, PsycINFO, Medline, EMBASE, ASSIA, Sociological Abstracts, Social Service Abstracts and Health Management Information Consortium. Intute: Social Science, Social Care Online and Google Scholar were used to identify Internet-based 'grey literature' (i.e. empirical research commissioned by governmental and non-governmental bodies published online) as well as journal papers not picked up by other databases. In order to maximize retrieval of relevant sources, the search was supplemented by the use of the snowballing technique whereby references to relevant publications were sought and reviewed for relevance and studies known to the research team, but which did not emerge from the initial searches, were also included. Most of these databases include only refereed journal articles; however, research-based books known to the research team were also used in the review.

The search strategy involved multiple keyword searches using the terms 'fathers', 'dads', 'men' or 'gender' with 'child protection', 'safeguarding', 'parenting', 'family services', 'family support' or 'child welfare'. The search was limited by language (English), date (2000-2010) and academic discipline (social sciences, social work, behavioural sciences). This initially yielded 415 publications. The abstracts and/or title of each publication were scanned to determine relevance to the research questions and publications were included if they were empirically based and focused on fathers (using the broadest definition of that term). Papers retained at this stage were then read in more detail to determine their relevance to the research questions. The majority of papers were excluded at this stage as they were based upon father involvement with health services or education as opposed to social 
interventions. Many papers were excluded as it was unclear to what extent the evidence related to fathers as opposed to 'parents' or 'mothers'. Some papers referred to fathers and yet only included one or two male participants opting instead to interview mothers about their perception about father behaviours. Papers were retained where they included evidence from fathers or child welfare service providers about father involvement and were based upon involvement with social work-related child welfare services.

Three hundred and eighty-three articles were excluded at this stage. All sources included were based either on primary empirical research or systematic reviews of empirical studies. Thirty studies which met the specified criteria were reviewed. Of these, four were systematic reviews, 16 were based on qualitative research, four were quantitative and six used mixed methods. It should be noted that whilst the bulk of the paper that follows is based on the search strategy described previously, there are also a couple of points where the studies referenced go beyond the scope of this search strategy, in order to add further evidence from a slightly different field. These studies are identified as such.

Data analysis was carried out in a transparent and systematic manner (Whittemore \& Knafl 2005). Firstly, publications were displayed on a table, allowing the comparison of country of origin, research design (including sample size, data collection instruments and setting) and results. Results were appraised as stronger or weaker according to clarity of reporting of research methods and close relevance to research questions. No predetermined quality criteria were used for research design and this might be regarded as a limitation of this review. Secondly, codes were generated inductively from the results column (Barnett-Page \& Thomas 2009), and developed into the nine themes in the findings below. Thirdly, the evidence in each theme was synthesized and developed with particular attention to evidence from the stronger studies, exceptions and anomalies. The results of this analysis follow.

\section{FINDINGS}

\section{What prevents fathers from engaging with child welfare services?}

\section{Good father - bad father}

In an analysis of the Serious Case Reviews conducted from April 2005 to March 2007 across England into the deaths or serious injuries of children where abuse or neglect were known or suspected, Brandon et al. (2009) found a tendency for professionals to adopt what they term 'rigid' or 'fixed' thinking. Fathers were labelled as either 'all good' or 'all bad', leading to attributions as to their reliability and trustworthiness. The consequences of such labelling prevented workers from taking views expressed by 'bad fathers' seriously. There were also apparent difficulties in how to label those fathers who had successfully completed interventions, especially as workers struggled to balance fathers' ability to change alongside past patterns of behaviour. Brandon et al. (2009) describe how these fathers can be labelled as 'reformed good dad' and present an example where a father was re-categorized following the successful completion of a domestic violence programme. In this case, an optimistic perspective became the dominant view and the relevance of previous risk information was not considered, with tragic results. This illustrates the process described by Ferguson \& Hogan (2004) where stories about fathers 'float around the system'. Using a case study approach of 24 vulnerable fathers, 12 mothers, 12 children and 20 professionals in Ireland, Ferguson and Hogan found that fathers' identities were sometimes constructed by professionals in collaboration with family members, with fathers often labelled as dangerous without the professional having had any direct contact with the man. Based upon this limited assessment, fathers were excluded. The diffusion of negative stories about fathers has also been found in an ethnographic study within a UK social work office, where Scourfield (2003) identified a number of pejorative discourses, including those of men as absent, irrelevant, a threat and no use (although some men were regarded more positively, in contrast to failing mothers, and some couples were seen to be 'as bad as each other'). O'Donnell et al. (2005), in a qualitative study in the USA, found that team members tend to reinforce each others' positive or negative construction of male service users. It can be seen in the studies reviewed in this section that similar patterns of labelling men have been found across a number of national settings.

\section{Mothers as gatekeepers}

Mothers can either facilitate or block access for both resident and non-resident fathers (O'Donnell et al. 2005; Huebner et al. 2008). In their study of 1958 US cases, Malm et al. (2006) found that only one third of mothers identified the father when asked. Drawing upon focus group evidence from individual cases with 
34 child welfare staff, US caseworkers outlined several reasons why a mother may choose not to provide this information (O'Donnell et al. 2005). These may include reluctance about letting the father know that child welfare services are involved, fear that the father may gain custody, anger at the father for being in a new relationship or fear of the father's reaction, particularly if there has been a history of domestic abuse. The decision to conceal a father's identity may also rest upon financial incentives, as the mother may receive more money informally from the father or assume she qualifies for more welfare benefits if his presence in the home is not known. This perception of financial disincentive to identify fathers is noted in Dominelli et al.'s (2011) study, which is based on qualitative interviews with 11 fathers of children in the Canadian public care system.

With regard to involving fathers in contact with child welfare professionals, a similar picture emerges whereby mothers may be reluctant to divulge information to social workers for fear that they may lose their children, not wish to include fathers if there has been a history of abuse or conflict between them or may be unwilling to involve fathers in what they perceive to be 'their territory' (Ferguson \& Hogan 2004). Findings from Huebner et al.'s (2008) mixed-method survey of 339 fathers and 1203 social service workers suggest that professionals need guidance on how to support mothers to manage the emotional nature of father involvement. A qualitative Canadian study of 22 caseworkers (Parent et al. 2007) found that more than half the caseworkers believed that the mother had the right to accept or refuse involvement from her partner.

In evaluating these findings, it is important to note that in some cases the mother may be perfectly justified in her fear, and some men will need to have contact with children restricted because of risk of serious harm. It should be noted that of course not all mothers will restrict access to fathers. Roskill (2008), in focus groups with 17 women service users from two English local authorities, found many of the women to be expressing strong views that the involvement of men with children's services was very important.

\section{Practitioners' traditional practices in relation to gender and parenting}

Child welfare workers tend to focus on mothers and exclude or at least make little effort to include fathers (Davidson-Arad et al. 2008; Strega et al. 2008;
Brandon et al. 2009). The prevalence of a view of mothers as the primary caretakers of children can be seen when more information is recorded about the mother, regardless of who is responsible for abusing the child or who the child lives with. Qualitative analysis of court petitions in Israel, for example, has shown that as many as two and a half times more words are recorded about mothers than fathers (Davidson-Arad et al. 2008). A mixed-method study of social work case files in Canada revealed that social workers deemed fathers to be irrelevant to mothers and children in $50 \%$ of cases and only $50 \%$ of those fathers who were seen as an asset to children were contacted (Strega et al. 2008). Low levels of engagement are also reported in relation to men who pose a risk to children. In Baynes \& Holland's (2010) English study of 40 child protection case files, over a third of fathers had no contact with a social worker prior to the first child protection meeting. In Roskill's (2011) file audit of cases involving domestically violent men, the father was neither seen nor contacted by phone in $32 \%$ of the core assessments studied. This means that little is known about fathers or other men in the household, their relationships with the mother and the extent to which they are involved with the children. Failure to know men in households has been a feature in serious case reviews (Brandon et al. 2009), where information about men has not been passed on or pursued by caseworkers.

In addition to men who are currently living with children, it is well documented that many birth fathers are not present in households where there are child welfare issues. Roskill's (2008) study of 67 case files (children in need, 'looked after' children and child protection) in two English local authorities found that in $80 \%$ of cases, the birth fathers were not part of the household where children were living. Practitioners do not always engage with fathers who are not living with their children. In Roskill's study, there was no information recorded about birth fathers in $20 \%$ of cases.

\section{Fathers as reluctant clients}

It is often supposed that fathers avoid contact with child welfare staff. O'Donnell et al. (2005), in their focus group study, note that caseworkers, from their experience, have a range of explanations for this avoidance. These include a fear that they cannot be good fathers for their children; a fear that involvement with the child welfare system will exacerbate their problems with the criminal justice system; fear that relationships with current partners not related to the child 
would be affected; fear of losing custody of children; and, for fathers in difficult circumstances, a perception that the system is not there to help them.

Some evidence is emerging of fathers' own perspectives. Schock \& Gavazzi's (2004) qualitative research in the USA noted, amongst many issues raised by fathers, the impact of their past experience with family services and their perception of their children's behaviour. Berlyn et al. (2008) also note, from their qualitative research with fathers and family welfare staff in Australia, that some men do not regard themselves as competent in child care and there is a tendency for men to be reticent about seeking or accepting help. Drawing on focus groups with fathers in the UK, Bayley et al. (2009) found that fathers' perceptions of help with parenting served as a barrier to their involvement. Fathers displayed concern that parenting programmes would dictate how they should parent and believed such groups were more suitable for mothers. Indeed, family centres and family support services tend to be perceived by fathers as mothers' places where women sit and chat (Ghate et al. 2000). Entering this largely female domain can make fathers feel self-conscious or intimidated (Ghate et al. 2000; Garbers et al. 2006; Berlyn et al. 2008). In a study carried out from 1998-1999 of 13 family centres in seven British local authorities, interviews with 90 fathers, mothers and staff found that in some cases, women felt that these centres were their domain and represented a safe place away from abusive partners, rendering them reluctant to welcome fathers into these groups (Ghate et al. 2000). In other cases, Ghate et al. found that fathers, especially the unemployed, valued the time they had alone while their partners and children attended such ventures.

\section{What facilitates father engagement with child welfare?}

\section{Early identification and involvement}

Early identification and involvement of fathers correspond with higher levels of engagement later on in the child welfare process (Garbers et al. 2006). In a qualitative study of vulnerable fathers in Ireland, Ferguson \& Hogan (2004, p. 13) note that ' $[w]$ ithout exception those professionals who were most successful in engaging fathers and "holding" them in the work were those who invited the father to attend from as close to the start as possible'. Father engagement within Sure Start programmes in the UK has also been found to be associated with early identification and involve- ment (Lloyd et al. 2003). To go beyond the limits of our search strategy, evidence on the importance of early identification of fathers on subsequent involvement with children's lives can be seen in the US Fragile Families and Child Well-being Study. Mincy et al. (2005) found that establishing paternity at birth was associated with greater father involvement in terms of contact, overnight stays and financial support. Whilst research findings suggest that fathers should be engaged in hospital at the time of their child's birth (Lloyd et al. 2003; Mincy et al. 2005), young fathers are often excluded at this time and some of those who request help do not receive it (Ashley et al. 2006). For young fathers without employment or educational prospects, fatherhood can offer them something meaningful which can help them to feel worthwhile (Ferguson \& Hogan 2004). These fathers may be keen to take on the role of father but may need help and support in making this transition. The research project Fathers Matter 3 (Ashley 2011), which includes an audit of 70 children in need and child protection cases as well as 10 focus groups with social work managers, social workers, mothers and fathers in the UK, found that young fathers appear to want help with negotiating relationships following the birth as well as support in caring for their offspring.

\section{A proactive approach to engaging fathers}

Drawing on data from a literature review as well as empirical data from fathers, practitioners and academic experts in the UK, Bayley et al. (2009) highlight the need to make services available to all fathers, including those who are employed. Drawing on qualitative evidence from in-depth interviews with 90 fathers, mothers and family centre staff, Ghate et al. (2000) found a mixed picture in relation to services' opening hours. They found opening hours to be less of an issue for fathers than they had anticipated, largely because most of the potential male service users were unemployed. Bayley et al. (2009) suggest flexibility of provision, as whilst 9-5 week day hours will be difficult for some, evenings and weekends may be difficult for others.

Those services which refuse to accept referrals without reference to fathers tend to have higher levels of father engagement, as found in Fabiano's (2007) systematic review of 32 studies of father involvement in behavioural parent training. Professional attitudes towards men further enhance engagement, so workers must be willing to include, invite and have positive attitudes towards working with fathers (Ghate et al. 
2000; Ashley et al. 2006). Interview findings from 162 parent support professionals from 12 local authorities found that the ways in which fathers were approached about engagement had a direct effect on their involvement. In this study, Cullen et al. (2011) provide support for findings that visiting fathers at home, being persistent and consulting fathers as to what services they required were effective strategies in increasing father engagement (Ghate et al. 2000; Berlyn et al. 2008; Bayley et al. 2009). In addition, Bayley et al.'s (2009) findings highlight the need to employ male staff, advertise in alternate locations such as sports centres, job centres or workplaces, and display positive images of fathers and their children. Various researchers have argued on the basis of their findings that active targeting of 'fathers' as opposed to 'parents' should be adopted (e.g. Lloyd et al. 2003; Berlyn et al. 2008). This strategy might help avoid the assumption that 'parents' means mothers, but it is also possible that some men will be less self-conscious about attending a service for all parents than one specifically for fathers, so caution is needed in the labelling of services.

One study of a preventive intervention provides support for both father-specific and inclusive services. Cowan et al. (2009) conducted a randomized control evaluation of an intervention to increase fathers' engagement. Participants included 289 couples with children under 7 years of age, primarily from lowincome Mexican American and European American families in California, who were recruited from family resource centres, other county service agencies, community advertisements and other community events where fathers were present. Participants were randomly assigned to either a 16-week group for fathers, a 16-week group for couples or a one-time informational meeting. Results from an 18-month follow-up demonstrated that both higher-dose interventions produced superior effects for fathers' engagement with their children, couple relationship quality and children's behaviour as compared with the lower-dose condition. However, only the parents from the couples' groups showed significant declines in parenting stress. It is important to emphasize, however, that this study was for preventive services, and working with couples together in a context where abuse or violence has already occurred may hold additional risks.

\section{Making services relevant to fathers}

In a US qualitative study on young fathers and risk, Weinman et al. (2002) found that of 128 fathers attending a social work programme, $73 \%$ were unemployed, $69 \%$ were school dropouts, nearly $40 \%$ had substance abuse problems and around 30\% had committed a crime. When asked about service needs, the majority of fathers wanted employment as they saw this as a way of establishing themselves as 'provider' and in turn, gaining access to their children. Despite the presence of multiple risk factors in these young men's lives, when asked, the young fathers did not perceive a need for parenting support or substance abuse counselling. Both Potter \& Carpenter (2010) and Cullen et al. (2011) describe the need for 'a hook' to draw men into parenting services, with Weinman et al. (2002) suggesting that employment may be one such effective 'hook' for young fathers. Other incentives include mental health or substance abuse intervention, and general health components (Weinman et al. 2002).

In their qualitative study of family centres in seven local authorities across England and Wales, Ghate et al. (2000) found that fathers preferred activitybased approaches which allowed them to spend time with their children and take part in outdoor activities or skill-based exercises. Levels of engagement were associated with fathers having a specific activity or objective such as a course or sporting activities. The National Evaluation of Sure Start in the UK supports these findings in that fathers were found to engage more in activity-based or outdoor activities than classroom-based parenting sessions or discussion groups (Lloyd et al. 2003). Magill-Evans et al.'s (2006) systematic review of the effectiveness of 12 interventions for fathers with infants or toddlers found that those interventions which involved active participation with children were associated with increased father-child interaction. More generally, research findings suggest that fathers prefer services that have been designed specifically for them, that provide the opportunity for them to spend time with their children and where they are able to access peer support (Ghate et al. 2000; Lloyd et al. 2003; Garbers et al. 2006; Bronte-Tinkew et al. 2007; Berlyn et al. 2008; Bayley et al. 2009). A recent mixed-method survey with 339 fathers and 1203 social workers involved in active child welfare cases in the USA revealed that fathers requested strengths-based, family-centred services (Huebner et al. 2008). It seems that in the context of family support work, the most effective interventions adopt a strengths-based approach which focus upon the important contribution fathers make to their children's lives where workers are positive about the father's ability and are 
honest about the issues faced yet which emphasize the father's existing skills and use solution-focused thinking to develop their skills and build confidence (Berlyn et al. 2008; Gearing et al. 2008).

\section{The effectiveness of interventions for maltreating fathers}

There is a certain lack of evidence about the effectiveness for fathers of parenting programmes which teach child management skills, as many programmes are attended only by mothers, as can be seen in a recent Cochrane review on interventions for teenage parents (Barlow et al. 2011). However, Lundahl et al.'s (2008) meta-analysis suggests that parent training programmes which fathers attend as well as mothers result in better child behaviour outcomes, although with fewer desirable gains for fathers than for mothers. In the context of child harm, however, it is not certain that interventions found to be effective with mothers will work as well with fathers, as there seem to be some distinctive features of men who maltreat children.

Quantitative findings from a relatively small study which is outside the scope of our search strategy suggest that maltreating fathers $(n=24)$ differ from non-maltreating fathers $(n=25)$ on a number of cognitive and affective constructs, including their experience and expression of anger, parenting stress and level of empathy with their children (Francis \& Wolfe 2008). In their mixed-method study of 53 fathers interviewed as part of the Integrative Assessment programme in the USA, Smithgall et al. (2009) found that those fathers described as being 'negatively involved resident fathers' did not understand the impact of their behaviour upon their children and were often resistant to services. These fathers were more likely to have been convicted of a violent crime with many reporting problems with substance abuse. Fathers who are abusive to women and children therefore pose particular challenges for practitioners. Given the distinctive features described, there would seem to be a certain logic to cognitive-behavioural interventions. These have been used to intervene with men who abuse women partners, with some modest success, as a meta-analysis of intervention studies has demonstrated (Babcock et al. 2004).

Scott \& Crooks (2007) have developed a 17-week programme specifically aimed at maltreating fathers, called 'Caring Dads'. The Caring Dads programme is currently in use in parts of the UK and draws upon an integration of research evidence on parenting, child maltreatment, readiness to change and domestic abuse (although there is consensus that this is not a domestic abuse perpetrator programme). Reporting findings from an initial pre-post test evaluation, Scott \& Crooks (2007) present promising results on certain measures with 45 fathers referred to Caring Dads in one city in Canada over a 1-year period. There was a significant decrease in the men's level of hostility, denigration and rejection of children, parenting stress and level of angry arousal in a family context. However, the current evidence base on the effectiveness of Caring Dads is slim (further evaluations are underway). Specialist programmes such as this are sometimes criticized because of the length of interventions, which do not suit all potential participants, and high dropout rates, but evidence-based specialist programmes for maltreating fathers would ideally be part of a menu of services social workers can choose from when working with fathers.

Field social workers also need approaches which will help them in routine casework and in areas where there may be no specialist programmes to which they can refer men. Although there is not any direct evidence of its effectiveness for engaging fathers in a child protection context, and introducing it here means going beyond the limits of our original search criteria, motivational interviewing (MI) has been found to be effective in allied fields such as substance misuse (Lundahl et al. 2010) and has considerable promise for the engagement of reluctant service users. $\mathrm{MI}$ is a client-centred yet directive style of therapeutic engagement which aims to enhance motivation to change through the resolution of ambivalence (Miller \& Rollnick 2002). It combines Rogerian humanistic relationship building with more active cognitive-behavioural strategies (Burke et al. 2003). MI has been used successfully with perpetrators of domestic violence to maintain attendance at programmes and reduce dropout (Taft et al. 2001) as well as increasing receptivity to programme activities (Musser et al. 2008; Kistenmacher \& Weiss 2009). It has also been applied to training of field social workers, in an attempt to reduce aggressive and confrontational styles of communication. Forrester et al.'s (2008a,b) mixed-method study of 40 social workers in a London borough showed a moderate level of success in improving practice 3 months posttraining where workers displayed lower levels of confrontation and higher levels of listening to parents. The MI skill level was low, however, and Forrester et al. (2008a) suggest that confrontational styles may be systemic in practice culture. Fathers who pose a 
risk to women and children are likely to be resistant to authoritarian social workers, so it may be that MI has potential to engage these men more successfully, allowing for more effective assessment and management of risk. Caution is needed, however. There is no direct evidence that $\mathrm{MI}$ is effective with fathers in a child protection context and it cannot be assumed that an approach that works in one field can necessarily be transferred to another. For example, Burke et al.'s (2003) meta-analysis of 30 clinical trials found that although MI was effective in alcohol treatment, the evidence did not support its use for HIV-related risk behaviours or smoking prevention.

\section{CONCLUSION}

It has been argued that one of the main obstacles to father involvement in the child protection process is dichotomous thinking, where men become labelled as either a 'risk' or 'resource' for their children as opposed to potentially a complex mix of both elements. Fathers may be excluded from child welfare work because of a pejorative practitioner culture, because mothers fail to identify them or are unwilling to include them, or because workers focus child welfare interventions upon the mother, possibly because of traditional assumptions about gender roles. In addition, fathers may avoid contact with workers, view parenting as the mother's role, or find that interventions are not focused upon their perceived needs or preferred activities. To overcome these barriers, the early identification and involvement of fathers appear to be a crucial first step in ensuring that they are contacted and understand that child welfare workers expect them to engage. In adopting a proactive approach to engaging fathers, there are various practical measures that can be employed, including offering flexible hours of services for working fathers, visiting them at home, being persistent and highlighting the positive gains to children of father involvement. With regard to service provision, the research evidence presented emphasizes the need for activity-based interventions where fathers can spend time with their children and where their strengths are built upon to positively enhance their fathering skills.

For maltreating fathers, the evidence suggests that fathers do not always understand the negative effects of their behaviour upon their children. Little is known about which approaches are the most effective, although there would seem to be a theoretical rationale for approaches which help fathers to consider their actions and how they affect others, perhaps on the basis of cognitive-behavioural principles. Whilst in its infancy within child welfare work, $M I$ is an approach that appears to lend itself to work with resistant clients. It may therefore hold some promise for the initial engagement of fathers who pose a risk to children, although it would be wise to proceed with caution.

The paper has not summarized the context of gendered power relations that is highlighted in many of the studies reviewed. The connection between mother blaming and father avoidance has been noted by several authors, for example Scourfield (2003) and Strega et al. (2008). It was beyond the scope of this review to synthesize these arguments, which are discussed in other overviews of the field (e.g. Featherstone 2009).

Although this review has concentrated on substantive findings, and has not paused to evaluate the methodological basis of studies, it will have been evident that there are both qualitative and quantitative studies into the issue of father engagement, but relatively little evidence which is focused on the effectiveness of interventions, especially in the context of risk. This is of course a difficult and sensitive issue to research, but we end the paper with a plea for more outcome studies, including those using experimental and quasiexperimental designs. Such studies are badly needed to inform the development of evidence-based policy and practice with fathers, although we note that the transferability of programmes to a different national and cultural context should not be assumed. In considering the evidence base for practice, it should also be noted that engaging fathers cannot be considered a discrete set of activities but part of wider engagement with families and crucially with mothers. There is therefore much to be learned from the broader interdisciplinary evidence base on the outcomes of child welfare services.

\section{ACKNOWLEDGEMENT}

The research was funded by the National Institute of Social Care and Health Research (Wales).

\section{REFERENCES}

Ashley, C. (ed.) (2011) Working with Risky Fathers: Fathers Matter 3: Research Findings on Working with Domestically Abusive Fathers and Their Involvement with Children' Social Care Services. Family Rights Group, London.

Ashley, C., Featherstone, B., Roskill, C., Ryan, M. \& White, S. (2006) Fathers Matter: Research Findings on Fathers and Their Involvement with Social Care Services. Family Rights Group, London. 
Babcock, J.C., Green, C.E. \& Robie, C. (2004) Does batterers' treatment work? A meta-analytic review of domestic violence treatment. Clinical Psychology Review, 23 (8), 1023-1053.

Barlow, J., Smailagic, N., Bennett, C., Huband, N., Jones, H. \& Coren, E. (2011) Individual and group based parenting programmes for improving psychosocial outcomes for teenage parents and their children. Cochrane Database of Systematic Reviews, (3), CD002964. doi: 10.1002/14651858. CD002964.pub2.

Barnett-Page, E. \& Thomas, J. (2009) Methods for the synthesis of qualitative research: a critical review. BMC Medical Research Methodology, 9 (59). Available at: http://www. biomedcentral.com/1471-2288/9/59 (accessed 23 January 2012).

Bayley, J., Wallace, L.M. \& Choudhry, K. (2009) Fathers and parenting programmes: barriers and best practice. Community Practitioner, 82 (4), 28-31.

Baynes, P. \& Holland, S. (2010) Social work with violent men: a child protection file study in an English local authority. Child Abuse Review. On-line publication ahead of print, doi: 10.1002/ car.1159.

Berlyn, C., Wise, S. \& Soriano, G. (2008) Engaging fathers in child and family services. Participation, perceptions and good practice. National Evaluation Consortium, Social Policy Research Centre, at the University of New South Wales, and the Australian Institute of Family Studies, Australia.

Brandon, M., Bailey, S., Belderson, P., Gardner, R., Sidebotham, P., Dodsworth, J. et al. (2009) Understanding Serious Case Reviews and Their Impact: A Biennial Analysis of Serious Case Reviews 2005-2007. Research report DCSF-RR129, London, DCFS.

Bronte-Tinkew, J., Carrano, J., Allen, T., Bowie, L., Mbawa, K. \& Matthews, G. (2007) Elements of promising practice for fatherhood programs: evidence-based research findings on programs for fathers. Gaithersburg.

Burke, B.L., Arkowitz, H. \& Menchola, M. (2003) The efficacy of motivational interviewing: a meta-analysis of controlled clinical trials. Fournal of Consulting and Clinical Psychology, 71 (5), 843-861.

Collins, J.A. \& Fauser, B.C.J.M. (2004) Editorial: balancing the strengths of systematic and narrative reviews. Human Reproduction Update, 11 (2), 103-110.

Cowan, P.A., Cowan, C.P., Pruett, M.K., Pruett, K. \& Wong, J.J. (2009) Promoting fathers' engagement with children: preventive interventions for low-income families. Fournal of Marriage and Family, 71 (3), 663-677.

Cullen, S.M., Cullen, A., Band, M., Davis, L. \& Lindsay, G. (2011) Supporting fathers to engage with their children's learning and education: an under-developed aspect of the Parent Support Adviser pilot. British Educational Research fournal, 37 (3), 485-500.

Daniel, B. \& Taylor, J. (2001) Engaging with Fathers: Practice Issues for Health and Social Care. Jessica Kingsley Publishers, London.

Davidson-Arad, B., Peled, E. \& Leichtentritt, R. (2008) Representations of fathers and mothers in court petitions for depen- dent minor status for children at risk. Children and Youth Services Review, 30, 893-902.

Dominelli, L., Strega, S., Walmsley, C., Callahan, M. \& Brown, L. (2011) 'Here's my story': fathers of 'looked after' children recount their experiences in the Canadian child welfare system. British Fournal of Social Work, 41 (2), 351-367. Advance access online, doi:10.1093/bjsw/bcq099.

Fabiano, G.A. (2007) Father participation in behavioral parent training for ADHD: review and recommendations for increasing inclusion and engagement. Fournal of Family Psychology, 21 (4), 683-693.

Featherstone, B. (2009) Contemporary Fathering: Theory, Policy and Practice. Policy Press, Bristol.

Ferguson, H. \& Hogan, F. (2004) Strengthening families through fathers: Developing policy and practice in relation to vulnerable fathers and their families. The Centre for Social and Family Research, Waterford Institute of Technology.

Forrester, D., McCambridge, J., Waissbein, C. \& Rollnick, S. (2008a) How do child and family social workers talk to parents about child welfare concerns? Child Abuse Review, 17, 23-35.

Forrester, D., McCambridge, J., Waissbein, C., Emlyn-Jones, R. \& Rollnick, S. (2008b) Child risk and parental resistance: can motivational interviewing improve the practice of child and family social workers in working with parental alcohol misuse? British Fournal of Social Work, 38, 1302-1319.

Francis, K.J. \& Wolfe, D.A. (2008) Cognitive and emotional differences between abusive and non-abusive fathers. Child Abuse and Neglect, 32, 1127-1137.

Garbers, C., Tunstill, J., Allnock, D. \& Akhurst, S. (2006) Facilitating access to services for children and families: lessons from Sure Start Local Programmes. Child E Family Social Work, 11 (4), 287-296.

Gearing, R.E., Colvin, G., Popova, S. \& Regehr, C. (2008) Re:Membering Fatherhood: evaluating the impact of a group intervention on fathering. Fournal for Specialists in Group Work, 33 (1), 22-42.

Ghate, D., Shaw, C. \& Hazel, N. (2000) Engaging Fathers in Preventive Services: Fathers and Family Centres. Joseph Rowntree Foundation, York.

Huebner, R.A., Werner, M., Hartwig, S., White, S. \& Shewa, D. (2008) Engaging fathers: needs and satisfaction in child protective services. Administration in Social Work, 32 (2), 87-103.

Kistenmacher, B.R. \& Weiss, R.L. (2009) Motivational interviewing as a mechanism for change in men who batter: a randomized controlled trial. Violence and Victims, 23 (5), 558570.

Lloyd, N., Lewis, C. \& O'Brien, M. (2003) Fathers in Sure Start. Department for Education and Skills, London.

Lundahl, B.W., Tollefson, D., Risser, H. \& Lovejoy, M.C. (2008) A meta-analysis of father involvement in parent training. Research on Social Work Practice, 18, 97-106.

Lundahl, B.W., Kunz, C., Brownell, C., Tollefson, D. \& Burke, B.L. (2010) A meta-analysis of motivational interviewing: twenty-five years of empirical studies. Research on Social Work Practice, 20 (2), 137-160. 
MacDonald, G. (2003) Using Systematic Reviews to Improve Social Care. SCIE reports no. 4, London: Social Care Institute for excellence. Available at: http://www.scie.org.uk/publications/ reports/report04.pdf (accessed 24 June 2011).

Magill-Evans, J., Harrison, M.J., Rempel, G. \& Slater, L. (2006) Interventions with fathers of young children: systematic literature review. Fournal of Advanced Nursing, 55 (2), 248-264.

Malm, K., Murray, J. \& Green, R. (2006) What about the Dads? Child Welfare Agencies' Efforts to Identify, Locate and Involve Nonresident Fathers. U.S. Department of Health and Human Services, Office of the Assistant Secretary for Planning and Evaluation, Washington, DC. Available at: http://aspe.hhs. gov/hsp/06/CW-involve-dads/index.htm (accessed 23 January 2012).

Miller, W.R. \& Rollnick, S. (2002) Motivational Interviewing: Preparing People for Change. Guilford Press, London.

Mincy, R., Garfinkel, I. \& Nepomynaschy, I. (2005) In-hospital paternity establishment and father involvement in fragile families. Fournal of Marriage and Family, 67 (3), 611-626.

Musser, P.H., Semiatin, J.N., Taft, C.T. \& Murphy, C.M. (2008) Motivational interviewing as a pregroup intervention for partner-violent men. Violence and Victims, 23 (5), 539-557.

O’Donnell, J.M., Johnson, W.E., D'Aunno, L.E. \& Thornton, H.L. (2005) Fathers in child welfare: caseworkers' perspectives. Child Welfare, LXXXIV (3), 387-414.

Parent, C., Saint-Jacques, M.C., Beaudry, M. \& Robitalle, C. (2007) Stepfather involvement in social interventions made by youth protection services in stepfamilies. Child E Family Social Work, 12 (3), 229-238.

Potter, C. \& Carpenter, J. (2010) Fathers' involvement in Sure Start: what do fathers and mothers perceive as the benefits? Practice: Social Work in Action, 22 (1), 3-12.

Roskill, C. (2008) Report on research on fathers in two children's services authorities. In: Fathers Matter Volume 2: Further Findings on Fathers and Their Involvement with Social Care Services (eds C. Roskill, B. Featherstone, C. Ashley \& S. Haresnape), pp. 19-54. Family Rights Group, London.

Roskill, C. (2011) Research in three children's services authorities. In: Working with Risky Fathers: Fathers Matter Volume 3: Research Findings on Working with Domestically Abusive Fathers and Their Involvement with Children's Social Care Services (ed. C. Ashley), pp. 29-80. Family Rights Group, London.
Ryan, M. (2000) Working with Fathers. Radcliffe Medical Press, Oxon.

Ryan, M. (2006) The experiences of fathers involved with social services departments: a literature review. In: Fathers Matter 1 Research Findings on Fathers and Their Involvement with Social Care Services (eds C. Ashley, B. Featherstone, C. Roskill, M. Ryan \& S. White), pp. 13-24. Family Rights Group, London.

Schock, A.M. \& Gavazzi, S.M. (2004) A multimethod study of father participation in family-based programming. In: Conceptualizing and Measuring Father Involvement (eds R.D. Day \& M.E. Lamb), pp. 129-159. Routledge, New York.

Scott, K.S. \& Crooks, C.V. (2004) Effecting change in maltreating fathers: critical principles for intervention planning. Clinical Psychology: Science and Practice, 10, 95-111.

Scott, K.S. \& Crooks, C.V. (2007) Preliminary evaluation of an intervention program for maltreating fathers. Brief Treatment and Crisis Intervention, 7 (3), 224-238.

Scourfield, J. (2003) Gender and Child Protection. Palgrave Macmillan, London.

Smithgall, C., DeCoursey, J., Gitlow, E., Yang, D., Jarpe-Ratner, E., Lansing, J. et al. (2009) Identifying, Interviewing, and Intervening: Fathers and the Illinois Child Welfare System. University of Chicago, Chicago.

Sonenstein, F., Malm, K. \& Billing, A. (2002) Study of Fathers' Involvement in Permanency, Planning and Child Welfare Casework. U.S. Department of Health and Human Services, Washington, DC.

Strega, S., Fleet, C., Brown, L., Dominelli, L., Callahan, M. \& Walmsley, C. (2008) Connecting father absence and mother blame in child welfare policies and practice. Children and Youth Services Review, 30 (7), 705-716.

Taft, C.T., Murphy, C.M., Elliot, J.D. \& Morrel, T.M. (2001) Attendance-enhancing procedures in group counselling for domestic abusers. Fournal of Counselling Psychology, 48 (1), 51-60.

Weinman, M.L., Smith, P.B. \& Buzi, R.S. (2002) Young fathers: an analysis of risk behaviours and service needs. Child and Adolescent Social Work fournal, 19 (6), 437-453.

Whittemore, R. \& Knafl, K. (2005) The integrative review: updated methodology. Fournal of Advanced Nursing, 52 (5), 546-553. 